EMANUEL MODOC

\title{
NAȚIONALIZAREA PRESTIGIULUI. LITERATURILE STRĂINE ÎN COMUNITĂȚILE PERIODICE ROMÂNEȘTI: 1919-1939*"
}

În cel mai recent volum al său, Galin Tihanov repetă o teză mai veche, pe care a vehiculat-o frecvent în ultimii cincisprezece ani: „Teoria literară modernă s-a născut în deceniile dintre cele două războaie mondiale în Europa Centrală și de Est" (Tihanov 2019 , p. 24). Dacă acesta e cazul, atunci ar fi de văzut cum poate fi evaluată absențta acestei teorii literare în spațiul românesc al aceleiași perioade. Investigații recente precum cea întreprinsă de Adriana Stan în volumul Bastionul lingvistic atribuie cvasiabsența sistemelor critice formaliste sau structuraliste influenței franceze dominante, prinsă ea însăși în lupta dintre pozitivism și intuiționism (Stan 2017, p. 29). O provocare, așadar, pentru cercetătorul interesat de „localizarea” teoriei literare în spațiul românesc este depășirea acestei probleme generate de morfologia culturală a zonei. Itinerariul conceptelor operaționale care au făcut parte, încă de la începutul secolului trecut, din bagajul teoretic al discursului critic autohton poate părea surprinzător dintr-o perspectivă „,distantă” asupra circulației ideilor literare.

Din această direcție voi încerca să ilustrez, în cele ce urmează, traseul acestor concepte operaționale, urmărind tiparele utilizării lor în publicistica românească dintre cele două războaie. Motivul din spatele alegerii acestui segment cultural (i.e. publicistica) ține de calitatea lui de a servi drept platformă pentru dezbaterile critice și teoretice, aspect cu atât mai important, cu cât întreaga tradiție critică românească de la începuturi până în contemporaneitate se sprijină pe dezvoltarea ei în foiletonistică. Pornind de la această premisă, e ușor de văzut cum tocmai în publicistică diseminarea conceptelor literare poate fi urmărită integral, atât în punctele ei de cotitură, cât și în rețea. Pentru studiul de caz expus mai jos, am ales să evit perspectiva istorică şi m-am concentrat asupra tiparelor care formează rețeaua conceptuală românească printr-un demers de „modelare tematică” (topic modelling), un tip de analiză exploratorie menită să releve așa-numitele „afinități elective” pe care cultura română le-a manifestat faţă de curentele culturale occidentale.

Un prim aspect care trebuie stabilit încă de la început vizează corpusul și metodologia utilizate în analiză. În ce privește corpusul, el este cuprins din totalitatea articolelor indexate în primul volum al BRLR, probabil cea mai comprehensivă bază de date creată cu scopul de a facilita studii comparative între cultura română și cele străine. În esență, BRLR inventariază după criterii tematice (Estetică, Curente literare, Istoria literaturii comparate etc.) orice articol care conține referințe la

\footnotetext{
* Lucrarea de față este o variantă în limba română, revizuită și contrasă, a unui articol în curs de publicare.
}

Caietele Sextil Puşcariu, V, 2021, Cluj-Napoca, p. 314-323 / DOI: 10.33993/csp.2021.5.309.319 
literaturi străine, un instrument deosebit de util atât pentru urmărirea la firul ierbii a traseului unui concept, cât și pentru analiza la scară „macro” a tuturor traseelor. Deoarece volumele care compun BRLR sunt organizate după o logică mai degrabă biblioteconomică, m-am rezumat la a analiza doar primul volum: doar acolo aspectele urmărite vizează dezbaterile generale din publicistică, și nu pe cele particulare, aplicate unor literaturi naționale. Apoi, două categorii de articole au fost omise din analiza mea: prima este cea a recenziilor, întrucât ele nu servesc la analiza tematică propusă; cea de-a doua vizează acele subiecte hiperspecializate care nu au atins un anumit prag cantitativ (pe care l-am stabilit la 10 articole/subiect) și care, astfel, nu au generat dezbatere în câmpul cultural românesc. Astfel, din cele 6455 de articole indexate în primul volum al BRLR, doar 2193 au fost procesate. Aceste articole, publicate în 268 de reviste din toate regiunile României Mari agregă, la rândul lor, nu mai puțin de 90 de subiecte, fiecare cu gradul lor de dominație în rețea (cele mai frecvente teme pot fi consultate în Tabel 1).

În cadrul studiilor Digital Humanities, modelarea tematică a început să fie utilizată relativ recent, una dintre cele mai timpurii analize aparținând lui Sharon Block și David Newman, care au întreprins o modelare tematică asupra întregii activități de secol XVIII a revistei „Pennsylvania Gazette”. Modelarea tematică, așa cum o înțeleg autorii acestei analize, se bazează pe ideea că orice document individual e compus dintr-unul sau mai multe „teme”. Prin utilizarea unor instrumente computationale, se pot obține anumite „clustere tematice” prin care documente cu conținut similar sunt reunite în ochiuri de rețea specifice (Block 2006). Fără a utiliza definiții predeterminate, modelarea tematică creează o listă de subiecte bazată pe ocurențe lexicale într-un corpus de text. Astfel, conținutul documentelor - și nu intervenția umană - e cel care determină tematizarea. Dezvoltările recente ale acestei metode computaționale au pătruns și în sfera studiului literaturii, cu explorări despre dramaturgia clasică franceză și engleză (Schöch 2017), despre poezia spaniolă (Navarro-Colorado 2018) și chiar despre istoriografia literară din publicistica culturală germană (Riddell 2014). În linia acestor abordări se află și scurta mea incursiune, în care - din motive ce țin de absența aproape totală a unor variante digitale utilizabile - am trecut de la conținutul propriu-zis al documentelor la metadatele lor. Având, așadar, un mediator uman care a indexat deja informațiile de care aveam nevoie, am reușit să cataloghez temele dezbătute mult mai uşor şi ocolind unele piedici specifice preparării de corpus digital.

Estetism
Estetică
Literatură pentru copii şi tineret
Clasicism
Dada
Decadență
Expresionism
Biografie romanțată
Futurism

\author{
Modernism \\ Specific național \\ Naturalism \\ Originalitate \\ Poetici \\ Literatura pornografică \\ Psihanaliză \\ Psihologism \\ Realism
}




\author{
Ermetism \\ Impresionism \\ Critică literară \\ Generații literare \\ Genuri literare \\ Tehnici literare \\ Teorie literară \\ Literatură și politică \\ Literatură și religie \\ Romanul modern \\ Poezia modernă
}

\author{
Renaștere, umanism, baroc \\ Romantism \\ Suprarealism \\ Simbolism \\ Relaţia dintre artă și moralitate \\ Funcția socială a literaturii \\ Condiția scriitorului \\ Teoria fictiunii \\ Tradiționalism \\ Teoria și tehnica traducerii \\ Opera de artă
}

Tabel 1. Lista subiectelor prevalente (cu peste zece articole/subiect) în publicistica românească din perioada 1919-1939

Cele nouăzeci de subiecte au fost procesate printr-un program de vizualizare în rețea, Gephi, care oferă reprezentări abstracte, dar bazate pe proprietățile „fizice” ale gradelor de apropiere dintre subiecte și reviste (determinate de cantitatea de articole dedicate unui subiect într-o anumită revistă), a rețelei tematice și conceptuale a publicisticii românești interbelice. Pentru a ilustra cât mai clar clusterele tematice formate, am aplicat un algoritm de modularitate, un tip de măsurătoare statistică a structurii rețelelor care favorizează formarea comunităților rețelare (vezi Figura 1). Scopul statisticii de modularitate este de a grupa nodurile de rețea pe baza relațiilor stabilite între ele (Cherven 2015). Se obțin astfel ochiuri tematice mult mai uşor de identificat.

Tiparele rezultate din măsurătorile statistice aplicate au dus la identificarea a două seturi distincte de receptare a subiectelor, pe care le-am grupat în „,comunități tematice”. Cincisprezece la număr, ele sunt compuse mai departe din ,subiecte dominante" și „subiecte secundare” cu care cele dominante formează ochiuri de rețea distincte (vezi Tabel 2). Văzute din perspectiva comunităților tematice formate, ele nu par a fi coerente la nivel de conținut semantic, însă aceste comunități relevă mai mult tiparele de interes a unor anumite reviste față de anumite subiecte. Din acest unghi, și revistele care antrenează anumite comunități tematice sunt de interes. De pildă, „Adevărul literar și artistic” angajează, ca principal ochi tematic, ,simbolismul”, pe când „Rampa nouă ilustrată” este responsabilă pentru agregarea comunității tematice dedicate „,condiției scriitorului”. Însă subiectele dominante reprezintă punctul de interes al analizei mele. Cel mai intens dezbătut subiect al publicisticii românești îl reprezintă, de departe, „teoria și tehnica traducerii”, cu peste 285 de articole dedicate acestei tematici, fenomen care poate fi atribuit, desigur, culturii translaționale a României (Cotter 2014). Alături de aceste articole, nu mai puțin de 18260 de texte literare (proză, poezie, dramaturgie, memorialistică etc.) au fost traduse din 26 de limbi între 1919 și 1944. Însă această cultură translațională nu poate fi confundată în mod automat cu condiția autocolonizatoare a României, ea dă și măsura influenței traducerilor în cadrul procesului de consolidare identitară a 
țării (Ursa 2017, p. 311). Un alt argument pentru relevanța subiectului traducerilor îl reprezintă raportul dintre producția de roman tradus și cea de roman autohton din aceeași perioadă. Andrei Terian observă, într-un studiu dedicat producției de roman în întreaga istorie a genului, că perioada 1918-1947 corespunde unei ,crize” postPrimul Război Mondial, urmată de o „explozie” a producției în anii '30 (Terian 2019 , p. 63). Pentru prima dată în cultura română, producția autohtonă de roman o surclasează pe cea a traducerilor. $\mathrm{Cu}$ toate acestea, așa cum se vede, „teoria și tehnica traducerii" figurează în continuare ca subiect de discuție dominant în publicistica românească. Acest fenomen confirmă în mare măsură evaluarea pe care Brian Baer o făcea culturilor est-central europene drept „culturi ale traducerii”, ale căror imperative sunt bazate pe „noțiunea de identitate comună extrapolabilă prin traducere [...], o metaforă eroică ce reprezintă atât un triumf asupra percepției de înapoiere, cât și un mod de a supraviețui” (Baer 2011, p. 10).

Același rol de legitimare identitară îl aveau și dezbaterile privitoare la „romantism", de vreme ce consolidarea identității culturale mergea mână în mână cu idealurile de universalitate ale curentului. Prevalența discuțiilor despre „estetică” servea, apoi, la întărirea tendințelor intuiționiste și anti-pozitiviste a criticilor perioadei, dublând și ca interfață a proiecțiilor culturale care căutau legitimarea estetică a unui „specific național”. În sfârșit, subiecte dominante precum „,critică literară”, „genuri literare” sau „tehnică literară” fac parte din arsenalul critic specific cotiturii meta-discursive premergătoare instituționalizării criticii literare românești din prima jumătate a secolului al XX-lea.

\begin{tabular}{|l|l|l|l|}
\hline \multicolumn{1}{|c|}{$\begin{array}{c}\text { Subiecte } \\
\text { dominante }\end{array}$} & Subiecte secundare & \multicolumn{1}{|c|}{$\begin{array}{c}\text { Subiecte } \\
\text { dominante }\end{array}$} & \multicolumn{1}{c|}{$\begin{array}{c}\text { Subiecte } \\
\text { secundare }\end{array}$} \\
\hline Genuri literare & $\begin{array}{l}\text { Neoclasicism } \\
\text { Sămănătorism } \\
\text { Impresionism (în } \\
\text { critică) }\end{array}$ & $\begin{array}{l}\text { Funcția socială a } \\
\text { literaturii }\end{array}$ & $\begin{array}{l}\text { Istoria artei } \\
\text { Dandyism }\end{array}$ \\
\hline Condiția scriitorului & $\begin{array}{l}\text { Suprarealism } \\
\text { Cubism } \\
\text { Dada } \\
\text { Constructivism } \\
\text { Memorie } \\
\text { Sensibilitate } \\
\text { Experimentalism } \\
\text { Literatură scrisă de } \\
\text { femei }\end{array}$ & $\begin{array}{l}\text { Relația dintre artă și } \\
\text { moralitate }\end{array}$ & $\begin{array}{l}\text { Estetism } \\
\text { Tezism } \\
\text { Curente literare }\end{array}$ \\
& $\begin{array}{l}\text { Literatură și revoluție } \\
\text { Teoria ficțiunii } \\
\text { Opera de artă } \\
\text { Literatura de război }\end{array}$ & & \\
& & \\
\end{tabular}




\begin{tabular}{|c|c|c|c|}
\hline Futurism & $\begin{array}{l}\text { Expresionism } \\
\text { Proletarizarea artei } \\
\text { Biografie romanțată } \\
\text { Mișcări literare }\end{array}$ & $\begin{array}{l}\text { Literatura } \\
\text { pornografică }\end{array}$ & $\begin{array}{l}\text { Pozitivism } \\
\text { Decadență } \\
\text { Tradiționalism } \\
\text { Autenticitate } \\
\text { Intimism } \\
\text { Literatură și politică }\end{array}$ \\
\hline Critică literară & $\begin{array}{l}\text { Clasicism } \\
\text { Profesionalizarea } \\
\text { literaturii } \\
\text { Neoromantism }\end{array}$ & Romantism & $\begin{array}{l}\text { Milieu } \\
\text { Poetici }\end{array}$ \\
\hline Estetică & $\begin{array}{l}\text { Istorism } \\
\text { Filosofia culturii } \\
\text { Teorie literară } \\
\text { Istoria esteticii } \\
\text { Organicism }\end{array}$ & Tehnici literare & $\begin{array}{l}\text { Imitație } \\
\text { Nihilism } \\
\text { Cenzură } \\
\text { Estetica folclorului } \\
\text { Renaștere, umanism, } \\
\text { baroc } \\
\text { Poetici corporale }\end{array}$ \\
\hline Poezia modernă & Sincretism & $\begin{array}{l}\text { Teoria şi tehnica } \\
\text { traducerii }\end{array}$ & $\begin{array}{l}\text { Filologie } \\
\text { Relații interculturale } \\
\text { Generaț̆ii literare } \\
\text { Critică tematică } \\
\text { Salonul literar } \\
\text { Weltliteratur } \\
\text { (Goethe) } \\
\text { Ideologie literară }\end{array}$ \\
\hline Romanul Modern & $\begin{array}{l}\text { Sincronism } \\
\text { Ermetism }\end{array}$ & Simbolism & $\begin{array}{l}\text { Geografie literară } \\
\text { Realism magic } \\
\text { Sociologie literară } \\
\text { Discursul crizei } \\
\text { Psihanaliză } \\
\text { Psihologism }\end{array}$ \\
\hline Modernism & $\begin{array}{l}\text { Originalitate } \\
\text { Realism socialist } \\
\text { Cosmopolitism } \\
\text { Materialism istoric }\end{array}$ & & \\
\hline
\end{tabular}

Tabel 2. Lista subiectelor dominante și a membrilor aferenți comunității lor

O altă direcție de analiză a tiparelor de receptare vizează tipologiile după care pot fi clasificate subiectele prevalente în publicistica românească. Pentru a măsura aceste tipologii, am stabilit două tipuri de indice. Primul este cel al „circulației teoretice", care se măsoară prin raportul dintre numărul de articole dedicate unui 


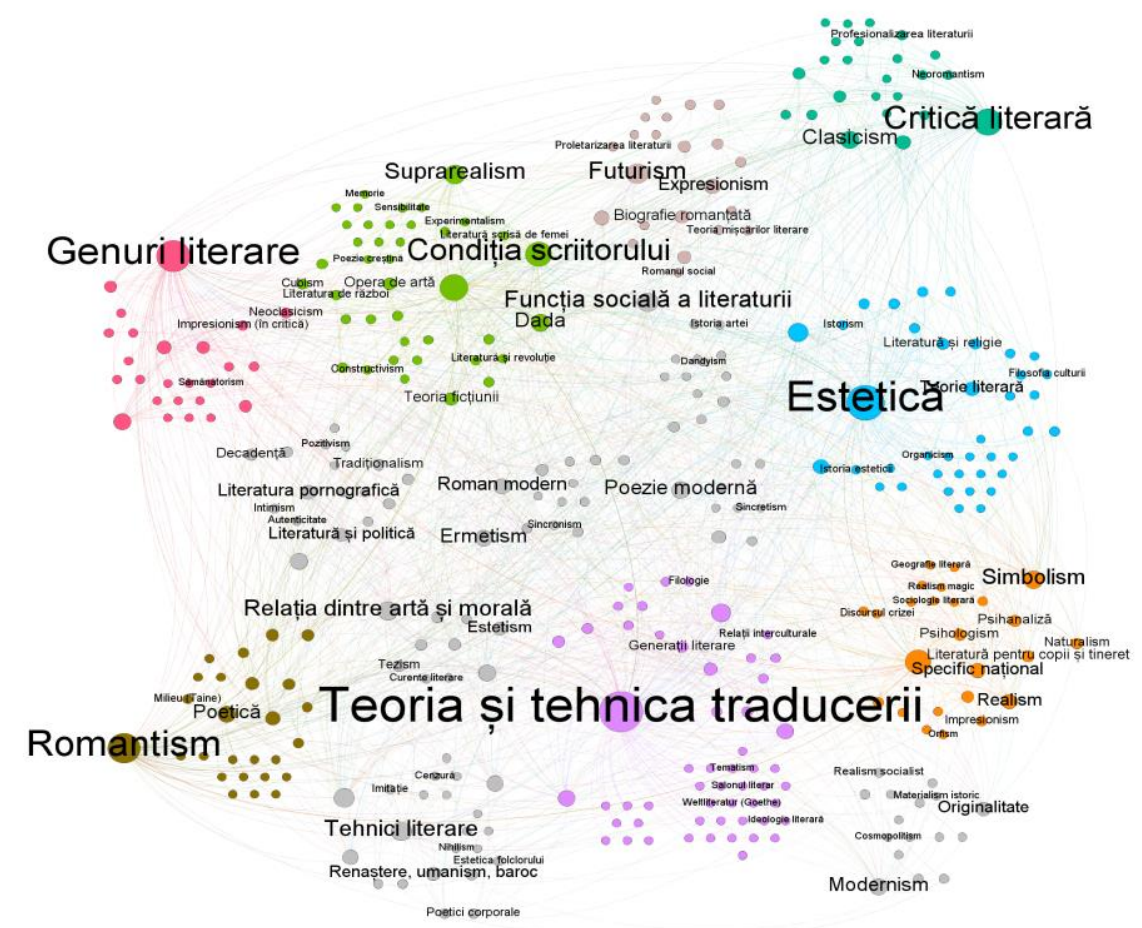

Figura 1. Rețeaua tematică a publicisticii românești din perioada 1919-1939. Mărimea etichetelor a fost ajustată la cantitatea de articole dedicate fiecărui subiect în parte

subiect și numărul total de reviste-gazdă. De exemplu, la un calcul al acestui raport în cazul „teoriei și tehnicii traducerii”, care se bucură de 285 de articole în 99 de publicații, putem vedea că are un Indice de Circulație Teoretică (ICT) de 2,87. Pentru a avea un cadru de referință, orice indice peste valoarea 2 indică un subiect care generează dezbateri semnificative într-o cultură țintă, în vreme ce un ICT între 1 și 1.99 indică concepte, teme sau dezbateri prea puțin consolidate în acel spațiu. Cel de-al doilea indice creat este cel al „noutății culturale”, care se referă la raportul dintre numărul de articole dedicate unui subiect și numărul de reviste care au găzduit doar câte un articol pe acel subiect. Într-o logică oarecum inversă, un Indice al Noutății Culturale (INC) mare indică un subiect cu un grad foarte scăzut de noutate culturală. Ca să revenim la subiectul dominant, „teoria și tehnica traducerii", acesta are un INC de 5.81, aşadar e un subiect cu grad extrem de scăzut de noutate în cultura românească. Datele de istorie literară confirmă această măsu- 
rătoare, dacă ne gândim că dezbaterile legate de traducere datează încă din a doua jumătate a secolului al XIX-lea.

Într-un mod oarecum previzibil, o bună parte din subiectele cu un indice ridicat de circulație teoretică au un indice scăzut de noutate culturală, indicând o relație de proporționalitate inversă între cele două variabile, însă acesta nu e cazul de fiecare dată. De pildă, „,clasicismul” are, prin istoricitatea inerentă a conceptului, un grad scăzut de noutate culturală, dar prezintă în același timp și un grad scăzut de circulație teoretică, reprezentând, aşadar, un subiect de interes terțiar în cultura română. La polul opus, ,poezia modernă” are un grad ridicat de noutate culturală, dar și un grad ridicat de circulație teoretică (un alt subiect relevant de discuție se leagă de discrepanțele de receptare dintre „poezia modernă” și „romanul modern”, vădind interesul cultural accentuat pentru poezie în detrimentul romanului). Sigur că noutatea unui concept într-o cultură dată e deosebit de relativă. „Futurismul”, un concept mai degrabă nou, de început de secol XX, are atât de multe articole în publicistica românească, încât indicele lui de noutate indică un subiect aproape clasat, pe când „expresionismul”, „dadaismul” și „suprarealismul” sunt veritabile noutăţi literare pentru cultura românească ${ }^{1}$. În același timp, se poate observa şi un grad foarte scăzut de potențial teoretic și de dezbatere din partea curentelor de avangardă, cel puțin pentru spațiul românesc. Istoriografia literară ne oferă suficiente date pentru a confirma acest tipar, însă aş adăuga și faptul că lipsa de dezbatere în jurul curentelor de avangardă oferă câteva indicii relevante și pentru lipsa dezbaterilor legate de formalism, de vreme ce, aşa cum nota Galin Tihanov, ,practicile literare avangardiste - fenomene deloc specifice strict spațiului est-central european - impuneau și declanșau procesul de raționalizare a acestora în teoria literară" (Tihanov 2004 , p. 80). Cele două valori, odată calculate pentru fiecare subiect dominant în parte, ne oferă două grafice, cred eu, relevante pentru tropismele de receptare a culturii române (vezi Figura 2 și Figura 3), întrucât relevă, prin cele două tipuri de receptare conceptuală, dinamicile gândirii moderne în România și afinitățile spațiului autohton în relație cu exigențele sale culturale și identitare.

În încheiere, aș spune că absența producției teoretice în spațiul românesc nu e un fenomen care poate fi atribuit unei indisponibilități culturale faţă de sisteme teoretice, ci mai degrabă ne arată că bătălia culturală în România era dusă pe un alt front. Dacă România - în calitatea ei de cultură minoră și translațională - nu a avut nimic de-a face cu nașterea teoriei literare moderne din regiune e pentru că figurile critice dominante (de la N. Iorga și G. Ibrăileanu la E. Lovinescu și G. Călinescu) operau în întregime într-un registru incompatibil cu crearea unor sisteme teoretice sau critice. Regionalizările teoretice care formează baza gândirii critice moderne în România nu e, astfel, rezultatul adaptării unor ideologii literare diferite, nici o strategie de ,reprezentare culturală” prin care literatura română (ca literatură

\footnotetext{
${ }^{1}$ Fenomenul se datorează unui caz aparte de receptare românească a unui fenomen literar-artistic străin, vezi Modoc 2020 pentru o explicație detaliată.
} 


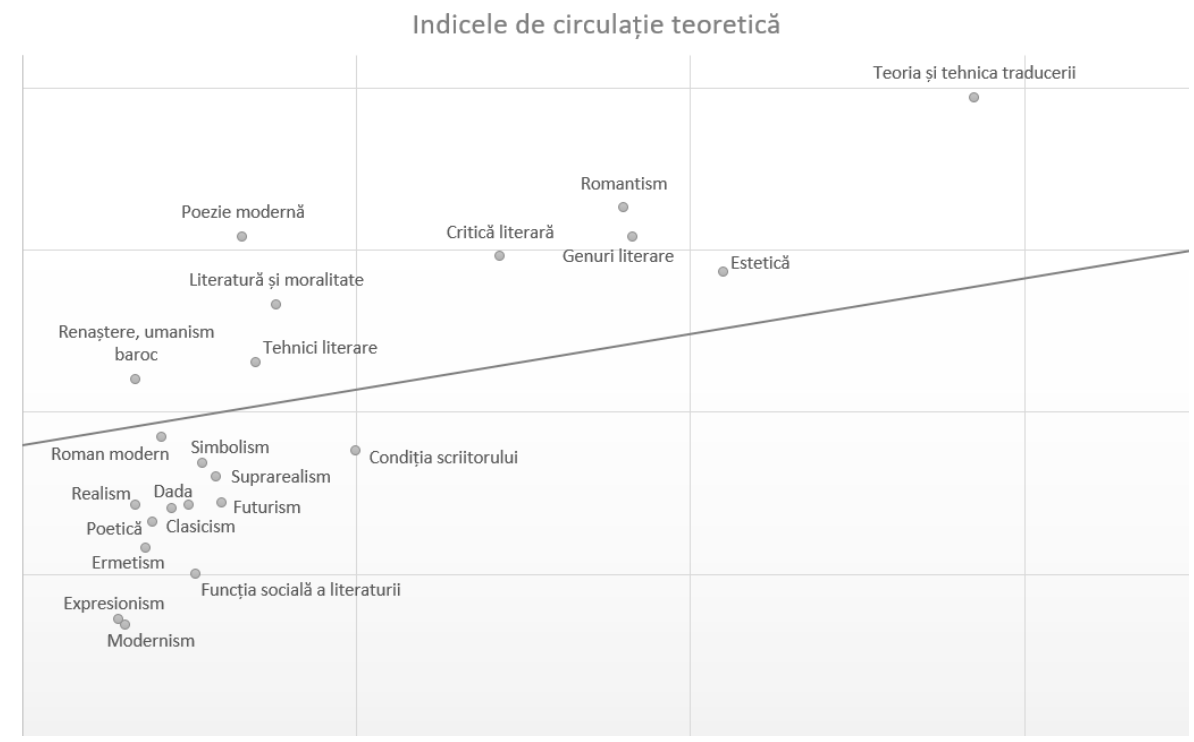

Figura 2. Distribuția subiectelor pe baza Indicelui de Circulație Teoretică.

Axa orizontală arată distribuția de la stânga la dreapta a cantității de articole dedicate fiecărui subiect, iar linia de referință indică subiectele productive (cele de deasupra liniei) și cele mai puțin productive (cele de sub linie)

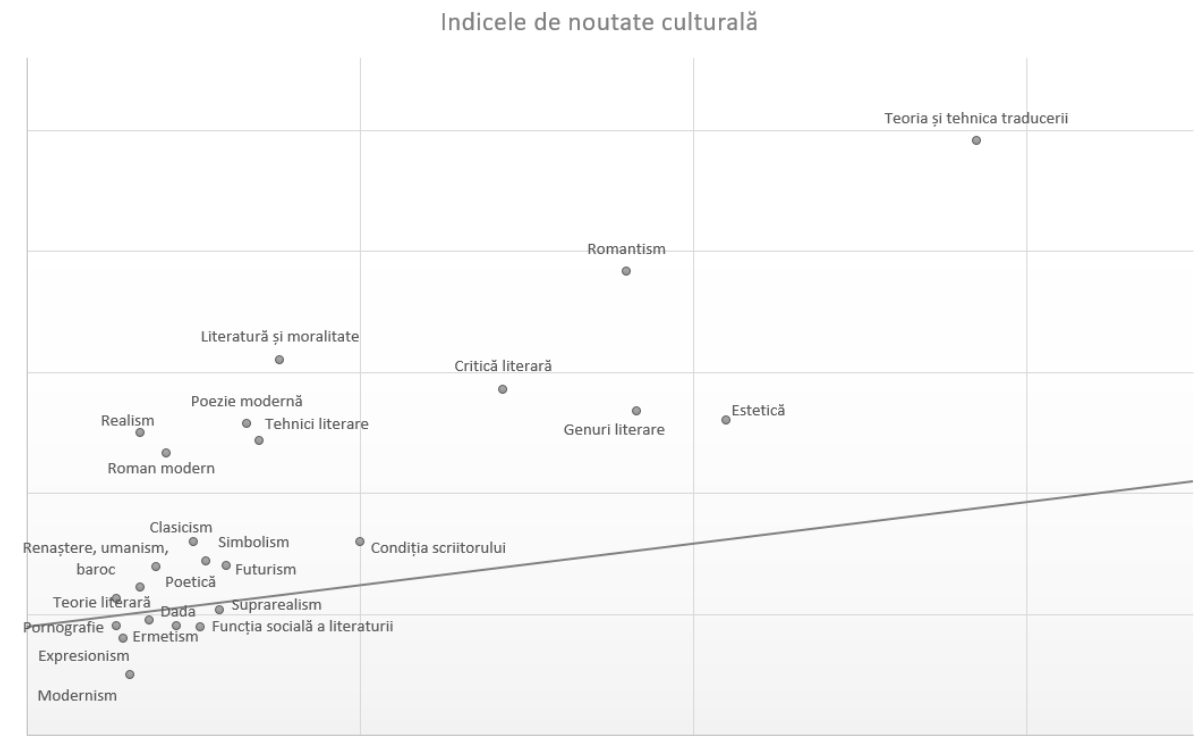

Figura 3. Distribuția subiectelor pe baza Indicelui de Noutate Culturală (INC).

Axa orizontală arată distribuția de la stânga la dreapta a cantității de articole dedicate fiecărui subiect, iar linia de referință indică noutatea (sub linie) sau, dimpotrivă, familiaritatea subiectelor (deasupra liniei) 
„națională”) încerca să obțină o poziție calculată în interiorul literaturii mondiale (Terian 2013, p. 4), ci mai degrabă o proiecție culturală cu ajutorul căreia concepte occidentale sunt gonflate și validate până la inventarea unor false naturalizări în cadrul culturii-țintă. Dublată de dimensiunea culturală translaţională dominantă a țării, cu rolul ei de a sincroniza creația artistică națională la Vest, producția teoretică a României servea la consolidarea identitară a culturii ei literare.

\section{SIGLĂ}

BRLR = Ana-Maria Brezuleanu, Viorica Nișcov, Michaela Șchiopu, Cornelia Ștefănescu, Bibliografia relațiilor literaturii române cu literaturile străine în periodice (1919-1944), vol. II, București, Editura Saeculum I. O., 1999.

\section{ABREVIERI BIBLIOGRAFICE}

Baer 2011 = Brian James Baer (ed.), Contexts, Subtexts and Pretexts: Literary Translation in Eastern Europe and Russia, Amesterdam, John Benjamins, 2011.

Block 2006 = Sharon Block, Doing More with Digitization. An Introduction to Topic Modeling of Early American Sources, în „Commonplace. The Interactive Journal of Early American Life”, 2006, vol. 6, nr. 2, p. 96-104.

Cherven $2015=$ Ken Cherven, Mastering Gephi Network Visualization, Birmingham, Packt Publishing, 2015.

Cotter 2014 = Sean Cotter, Literary Translation and the Idea of a Minor Romania, New York, University of Rochester Press, 2014.

Navarro-Colorado 2018 = Borja Navarro-Colorado, On Poetic Topic Modeling: Extracting Themes and Motifs from a Corpus of Spanish Poetry, în „Frontiers in Digital Humanities”, 2018, vol. 5, nr. 15, https://www.frontiersin.org/articles/10.3389/fdigh.2018.00015/full. Accesat în 20 noiembrie 2021.

Riddell 2014 = Allen Riddell, How to Read 22,198 Journal Articles: Studying the History of German Studies with Topic Models, în Matt Erlin and Lynne Tatlock (eds.). Distant Readings: Topologies of German Culture in the Long Nineteenth Century, Rochester \& New York, Camden House, 2014, p. 91-114.

Schöch 2017 = Christof Schöch, Topic Modeling Genre: An Exploration of French Classical and Enlightenment Drama, în „Digital Humanities Quarterly”, 2017, vol. 11, nr. 2, http://www. digitalhumanities.org/dhq/vol/11/2/000291/000291.html. Accesat în 20 noiembrie 2021.

Stan 2017 = Adriana Stan, Bastionul lingvistic. O istorie comparată a structuralismului în România, București, Editura Muzeul Literaturii Române, 2017.

Terian 2013 = Andrei Terian, National Literature, World Literatures, and Universality in Romanian Cultural Criticism 1867-1947, în „CLCWeb”, 2013, vol. 15, nr. 5, https://docs.lib.purdue. edu/cgi/viewcontent.cgi?article=2344\&context=clcweb. Accesat în 20 noiembrie 2021.

Terian 2019 = Andrei Terian, Big Numbers. A Quantitative Analysis of the Development of the Novel in Romania, în „Transylvanian Review”, XXVIII, 2019, supl. nr. 1, p. 56-71.

Tihanov 2004 = Galin Tihanov, Why Did Modern Literary Theory originate in Central and Eastern Europe? (And Why is it Now Dead), în „Common Knowledge”, 2004, vol. 10, nr. 1, p. 61-81.

Tihanov $2019=$ Galin Tihanov, The Birth and Death of Literary Theory. Regimes of Relevance in Russia and Beyond, Stanford, Stanford University Press, 2019.

Ursa 2017 = Mihaela Ursa, Made in Translation: A National Poetics for the Transnational World, în Mircea Martin, Christian Moraru, Andrei Terian (Ed.), Romanian Literature as World Literature, New York, Bloomsbury, 2017, p. 309-325. 


\section{NATIONALIZING PRESTIGE. FOREIGN LITERATURES IN THE ROMANIAN PERIODICAL COMMUNITIES: 1919-1939 (Abstract)}

Drawing from recent developments in the field of World Literature, but also earlier attempts at mapping local cultural traditions, contexts, and affinities, my proposal attempts to investigate the dominant patterns of cultural criticism within the literary publications active during the interwar period. Using an exhaustive resource of metadata related to the relations between Romanian literature and foreign literatures developed over the span of twenty years, I will plot a network abstraction focused on revealing patterns and trends of reception within Romanian cultural magazines. This process of "topic modelling" cultural criticism will serve to illustrate the dominant subject matters present in the Romanian cultural press. Following my data analysis, I will attempt to provide an explanatory model of "theory production" in Romanian literary culture that accounts for the seemingly "ahistorical" nature of autochthonous localizations.

Cuvinte-cheie: comunități periodice, modelare tematică, Digital Humanities, lectură distantă, presă literară românească.

Keywords: periodical communities, topic modelling, Digital Humanities, distant reading, Romanian literary press.

Institutul de Lingvistică și Istorie Literară „Sextil Puşcariu” al Academiei Române

Cluj-Napoca, str. E. Racoviţă, 21

isp.emanuelmodoc@gmail.com 